\title{
DÜBLIN
}

Technological University Dublin

ARROW@TU Dublin

2010-10-01

\section{Microstrip-fed Wideband Circularly Polarized Printed Antenna}

\author{
Xiulong Bao \\ Technological University Dublin, xiulong.bao@tudublin.ie \\ Max Ammann \\ Technological University Dublin, max.ammann@tudublin.ie \\ Patrick McEvoy \\ Technological University Dublin, patrick.mcevoy@tudublin.ie
}

Follow this and additional works at: https://arrow.tudublin.ie/ahfrcart

Part of the Electrical and Electronics Commons, Electromagnetics and Photonics Commons, and the Systems and Communications Commons

\section{Recommended Citation}

Bao, X., Amman, M., McEvoy, P. (2010) Microstrip-fed Wideband Circularly Polarized Printed Antenna. IEEE Transactions on Antennas \& Propagation, vol. 58, no. 10, pp 3150-3156. doi:10.1109/TAP.2010.2055776

This Article is brought to you for free and open access by the Antenna \& High Frequency Research Centre at ARROW@TU Dublin. It has been accepted for inclusion in Articles by an authorized administrator of ARROW@TU

Dublin. For more information, please contact

arrow.admin@tudublin.ie, aisling.coyne@tudublin.ie, gerard.connolly@tudublin.ie. Funder: Science Foundation Ireland

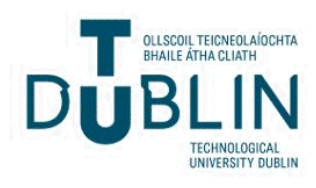




\title{
Microstrip-Fed Wideband Circularly Polarized Printed Antenna
}

\author{
Xiu Long Bao, Member, IEEE, Max J. Ammann, Senior Member, IEEE, and Patrick McEvoy, Member, IEEE
}

\begin{abstract}
A wideband circularly-polarized printed antenna is proposed, which employs an asymmetrical dipole and a slit in the ground plane which are fed by an L-shaped microstrip feedline using a via. The proposed antenna geometry is arranged so that the orthogonal surface currents, which are generated in the dipole, feedline and ground plane, have the appropriate phase to provide circular polarization. A parametric study of the key parameters is made and the mechanism for circular polarization is described. The measured results show that the impedance bandwidth is approximately $1.34 \mathrm{GHz}(2.45 \mathrm{GHz}$ to $3.79 \mathrm{GHz})$ and the $3 \mathrm{~dB}$ axial ratio bandwidth is approximately $770 \mathrm{MHz}(2.88 \mathrm{GHz}$ to $3.65 \mathrm{GHz})$ which represent fractional bandwidths of approximately $41 \%$ and $23 \%$, respectively, with respect to a centre frequency of $3.3 \mathrm{GHz}$.
\end{abstract}

Index Terms-Asymmetrical dipole, circular polarization, printed dipole antenna, slot antenna.

\section{INTRODUCTION}

C IRCULARLY polarized (CP) radio propagation links in satellite communications, satellite positioning and radio frequency identification (RFID) [1]-[3] systems are preferred to linear polarization schemes which are subject to losses when arbitrary polarization misalignment occurs between the transmitter and receiver. With CP antennas at both radios, the enhanced gain and cross-polar discrimination improve the resilience of the system to multipath propagating effects. To create circular polarization, the antenna must radiate from modes of equal magnitude that are orthogonal in space and in phase quadrature. Several techniques have been used in various types of circularly polarized antennas that have been reported in recent decades. Printed circular or square patch geometries with perturbing narrow slots or truncated stubs [4], [5] achieve $\mathrm{CP}$ by introducing degenerate modes with $90^{\circ}$ phase difference. To create broader operating bandwidths, designs have included paired rectangular wire loops above an infinite ground plane [6], a coupled loop with parasitic loop [7] and a two-layer substrate [8], where axial ratio (AR) bandwidths of $18 \%, 16 \%$ and $9.6 \%$ respectively, were achieved. Furthermore, balanced

Manuscript received December 08, 2008; revised March 18, 2009; accepted April 13, 2010. Date of publication July 01, 2010; date of current version October 06, 2010. This work was supported in part by Science Foundation Ireland under Grants 08/CE/I1523 and 09/SIRG/I1644. The Telecommunications Research Centre, CTVR, provided the research infrastructure.

X. L. Bao is with the Antenna and High Frequency Research Centre, Dublin Institute of Technology, Dublin 8, Ireland

M. J. Ammann and P. McEvoy are with the Antenna and High Frequency Research Centre, Dublin Institute of Technology, Dublin 8, Ireland and also with the Telecommunications Research Centre, Dublin 8, Ireland (e-mail: ammann@ieee.org).

Color versions of one or more of the figures in this paper are available online at http://ieeexplore.ieee.org.

Digital Object Identifier 10.1109/TAP.2010.2055776

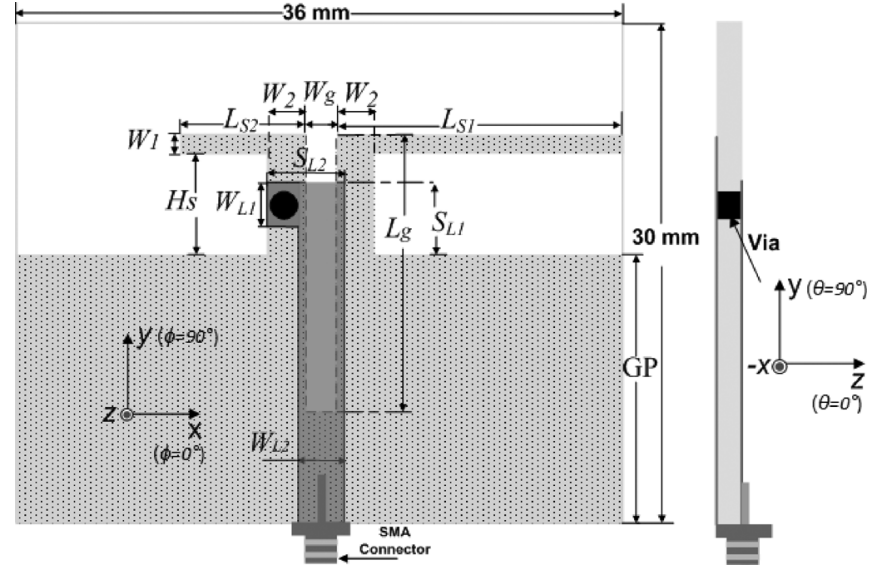

Fig. 1. Geometry and coordinate system for the proposed printed antenna. (a) The asymmetrical dipole and microstrip feedline network with a slit in the ground plane. (b) Edge profile.

dual circular and rhombic loops with small parasitic elements [9] use gaps in the structure to achieve circular polarization with AR bandwidths up to $40 \%$, but at a cost of the antenna profile being greater than a quarter-wavelength. Alternatively, lower profile slot antennas [10]-[13] have achieved CP bandwidth characteristics that have AR bandwidths that range from $4 \%$ to $25 \%$.

The literature also reports coupled feed designs for CP performance. An annular-ring patch element with a parasitic fan-shaped patch [14] is excited by a single port; and a two-port U-shaped microstrip feedline couples into square and circular annular ring patches to provide reconfigurable polarization sense, depending on which port is driven [15]. In both cases, the operational bandwidths are less than $2 \%$. These performances contrast with various printed dipole antennas with broad bandwidths, low-profiles and light weights, but linear polarization. In [16]-[19], the printed dipole antennas have integrated microstrip baluns and in [20] the dual-band printed dipole antennas comprise a pair of arms with two parallel strips. In [21], by using four sequentially rotated configurations of the crossed dipole, circularly polarized characteristics are realized. In this paper, a simple single layer printed dipole with a pair of asymmetrical arms is combined with a slot antenna to provide circular polarization. A parametric study is made to optimize the performance of the small structure to realize a $23 \%$ AR bandwidth.

\section{GeOMetry of the Proposed PRinted CP ANTENNA}

The geometry and coordinate system of the proposed printed circularly polarized antenna are shown in Fig. 1. 


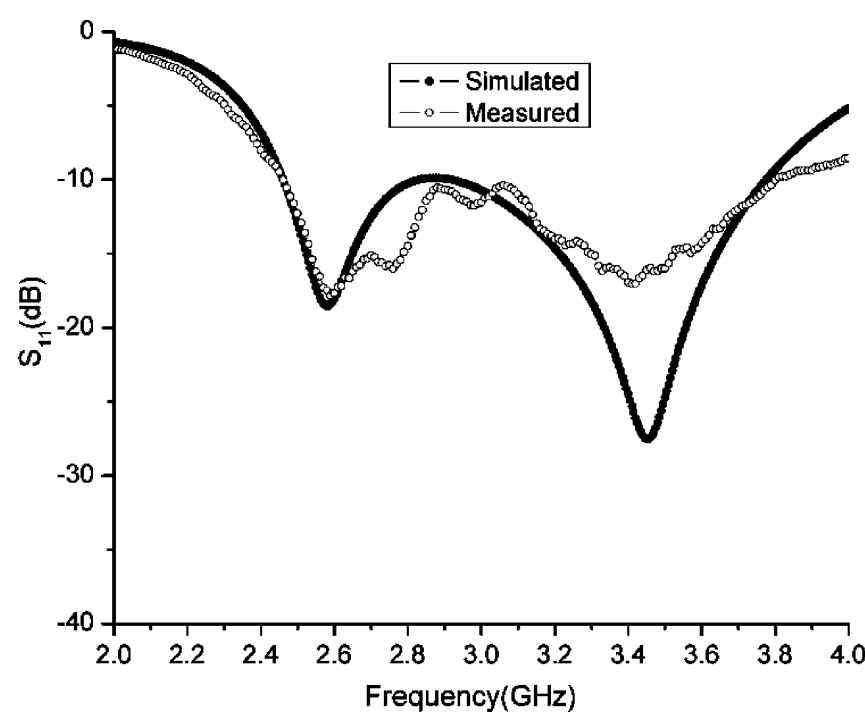

Fig. 2. The simulated and measured $\mathrm{S}_{11}$ for the proposed dipole antenna.

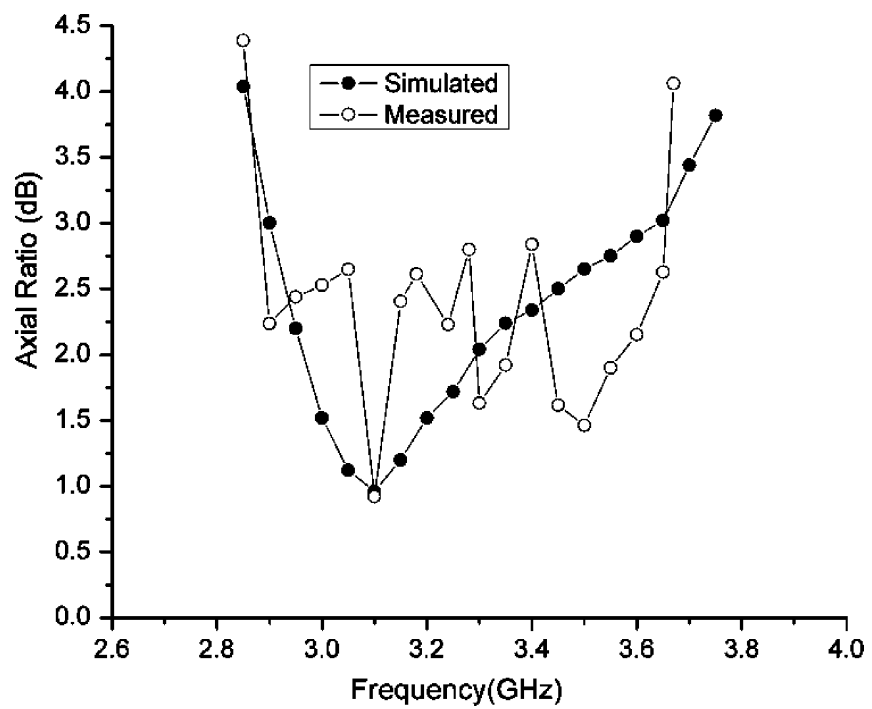

Fig. 3. The simulated and measured axial ratio for the proposed dipole antenna.

The L-shaped microstrip feedline is printed on one side of the substrate and an asymmetrical dipole with ground plane is printed on the rear side. The narrow dipole gap is continued between a pair of coplanar strip lines and it extends as a slit into the small ground plane. The microstrip feedline extends above the groundplane to an orthogonal stub which is connected to the short arm of the dipole by means of a via. The microstrip feedline is wider than the dipole gap and it is centered opposite the groundplane slit, which is also centered on the substrate. The feed configuration differs from a conventional microstrip-via balun which simply couples to one dipole feedline [17]. In our case, the overlap between the microstrip edges and the slit edges introduces coupling to alter the surface current densities and phasing along the feed network. The feed network functions in two ways. Firstly, it enables an impedance transformation, between $50 \Omega$ at the microstrip feed port and the higher dipole impedance, across a wide frequency range. Secondly, it supports orthogonal radiating currents of similar magnitude but

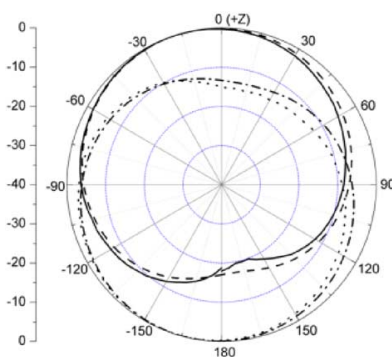

(a)

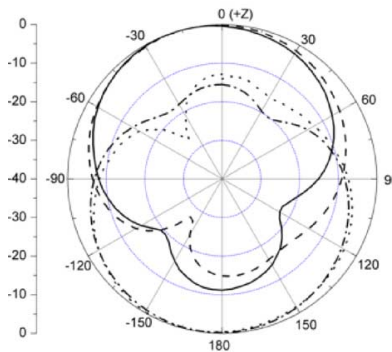

(c)

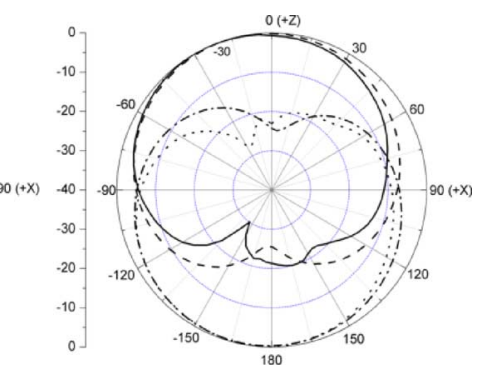

(b)

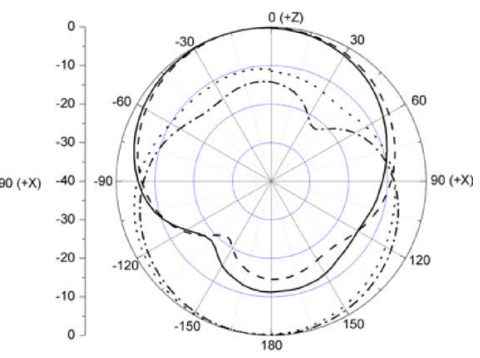

(d)
Fig. 4. Simulated and measured radiation patterns in the $x z$ Elevation Plane $\left(\varphi=0^{\circ}\right.$ ) at (a) $2.9 \mathrm{GHz}$, (b) $3.1 \mathrm{GHz}$, (c) $3.3 \mathrm{GHz}$ and (d) $3.5 \mathrm{GHz}$. Simulated RHCP — — - ; Measured RHCP_ sured LHCP ..........

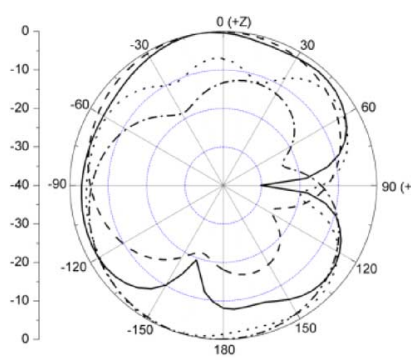

(a)

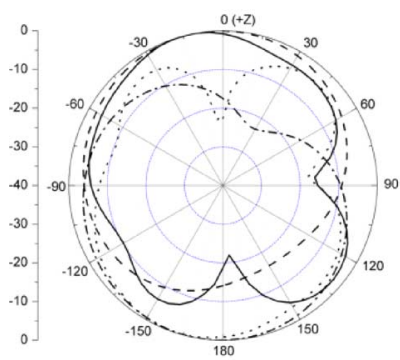

(c)

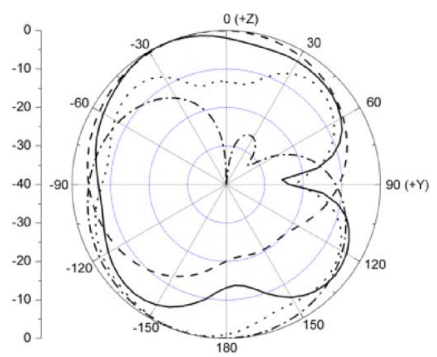

(b)

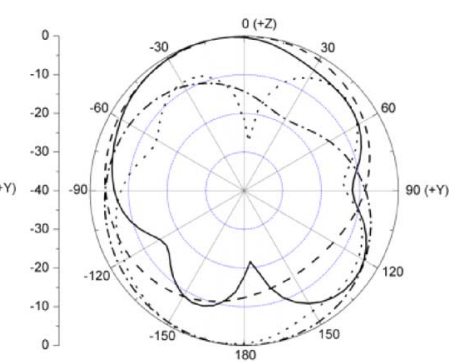

(d)
Fig. 5. Simulated and measured radiation patterns in the $y z$ Elevation Plane $\left(\varphi=90^{\circ}\right)$ at (a) $2.9 \mathrm{GHz}$, (b) $3.1 \mathrm{GHz}$, (c) $3.3 \mathrm{GHz}$ and (d) $3.5 \mathrm{GHz}$. Simulated RHCP — - - ; Measured RHCP — ; Simulated LHCP — - — ; Measured LHCP ...........

in phase quadrature to those on the asymmetrical dipole, thereby stimulating radiation in the $x$ and $y$ directions.

The longer arm of the printed dipole, the ground plane slit and the microstrip feedline are approximately a quarter wavelength. The proposed antenna is printed on a Taconic RF35 substrate, with a relative permittivity of 3.5 , a thickness of $1.57 \mathrm{~mm}$ and a loss tangent of 0.0018 . The substrate size is $30 \mathrm{~mm} \times 36 \mathrm{~mm}$. The geometric parameters and modeled features are detailed in Fig. 1. The diameter of the via is $1.4 \mathrm{~mm}$ and it is centered with respect to both the microstrip and the dipole feedline. 
TABLE I

\begin{tabular}{lcc}
\hline \multicolumn{1}{c}{ PARAMETER } & LABEL & DIMENSION (MM) \\
\hline Dipole Width & $W_{1}$ & 1.0 \\
Dipole Feed Width & $W_{2}$ & 2.0 \\
Dipole Gap & $W_{g}$ & 2.0 \\
Microstrip Stub Width & $W_{L 1}$ & 3.0 \\
Microstrip Feedline Width & $W_{L 2}$ & 3.0 \\
Long Dipole Length & $L_{S 1}$ & 17.0 \\
Short Dipole Length & $L_{S 2}$ & 8.0 \\
Dipole-Groundplane Separation & $H_{S}$ & 6.0 \\
Groundplane Slit Length & $L_{g}$ & 12.0 \\
Microstrip Stub Length & $S_{L 1}$ & 4.0 \\
Microstrip-Groundplane Separation & $S_{L 2}$ & 4.5 \\
Groundplane Length & $G P$ & 16.0 \\
\hline \hline
\end{tabular}

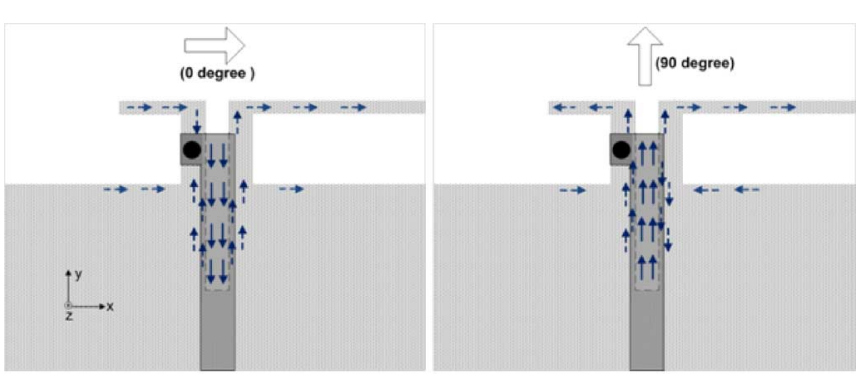

(a)

(b)

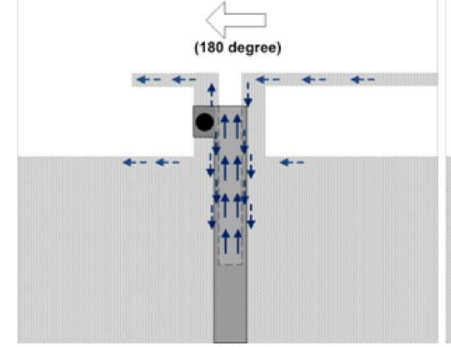

(c)

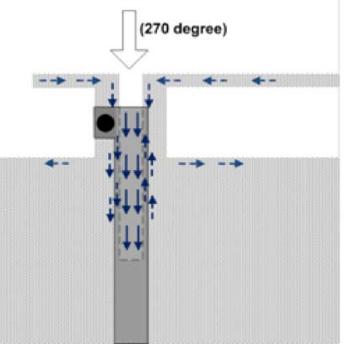

(d)

Fig. 6. Simulated surface current distributions for antenna orthogonal phases. (a) $0^{\circ}$, (b) $90^{\circ}$, (c) $180^{\circ}$ and (d) $270^{\circ}$. ( $\rightarrow$ solid line of arrows on the microstrip line; $-\rightarrow$ dash line of arrows on the back of the substrate).

\section{Numerical AND MEASURED Results}

Numerical work was carried out using the time domain solver in CST Microwave Studio and included a SMA feed connector model. The dimensions for the dipole, ground plane and feedline parameters are given in Table I. The simulated and measured $\mathrm{S}_{11}$ values for the proposed antenna are given in Fig. 2 and show good agreement. The measured $-10 \mathrm{~dB} \mathrm{~S}_{11}$ bandwidth was found to be approximately $1.34 \mathrm{GHz}$ (i.e., $2.45 \mathrm{GHz}$ to $3.79 \mathrm{GHz}$ ). In this case, the antenna was designed to realize right-hand circular-polarization (RHCP) in the $+z$ direction. The RHCP and left-hand circular-polarization (LHCP) radiation patterns and AR were measured in an anechoic chamber using a standard gain horn antenna as a reference and computed using data from their far field components $\mathrm{E}_{\theta}$ and $\mathrm{E}_{\varphi}$ using formulae from [22].The measured AR is shown in Fig. 3 along with numerical predictions. It can be seen that the measured $3 \mathrm{~dB} A R$ bandwidth is approximately $770 \mathrm{MHz}$ (i.e., $2.88 \mathrm{GHz}$ to 3.65 $\mathrm{GHz}$ ) and is in agreement with numerical values. The RHCP

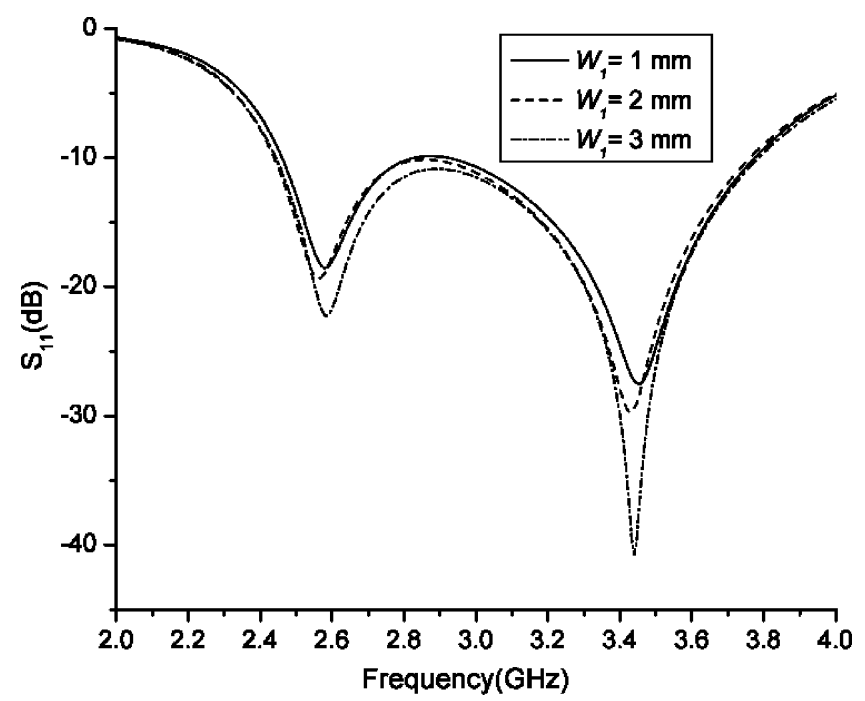

(a)

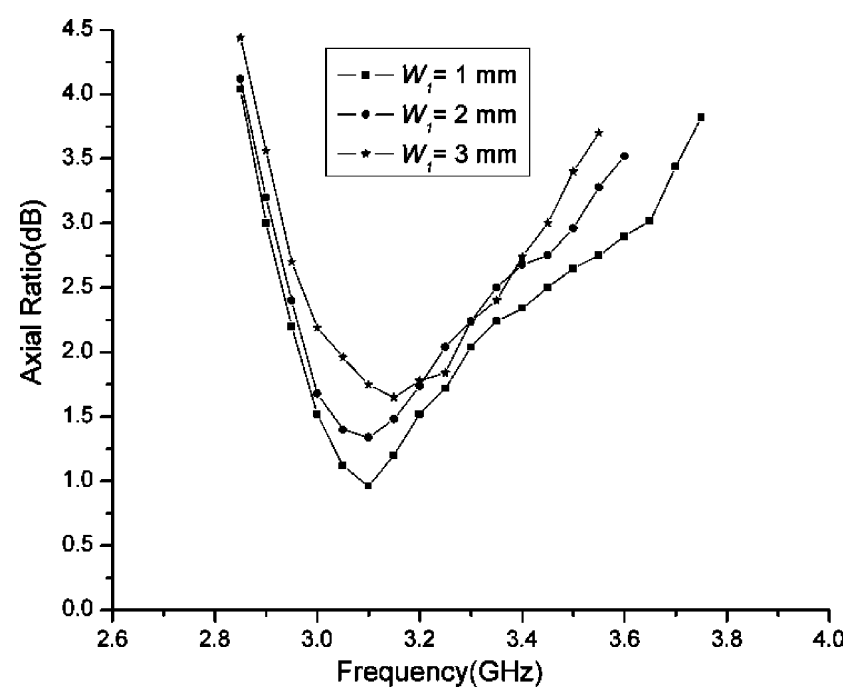

(b)

Fig. 7. (a) Comparison of the $\mathrm{S}_{11}$ with different widths $W_{1}$ of printed arms and with $L_{S 2}=8.0 \mathrm{~mm}, L_{g}=12.0 \mathrm{~mm}, W_{g}=2.0 \mathrm{~mm}, S_{L 1}=4.0 \mathrm{~mm}$. (b) Comparison of the AR with different widths $W_{1}$ of printed arms and with $L_{S 2}=8.0 \mathrm{~mm}, L_{g}=12.0 \mathrm{~mm}, W_{g}=2.0 \mathrm{~mm}, S_{L 1}=4.0 \mathrm{~mm}$.

and LHCP radiation patterns were measured in the $\varphi=0^{\circ}$, $90^{\circ}$ planes (antenna co-ordinates, $x z$ and $y z$ respectively) at frequencies of $2.9 \mathrm{GHz}, 3.1 \mathrm{GHz}, 3.3 \mathrm{GHz}$ and $3.5 \mathrm{GHz}$. These were normalized and compared to simulated patterns and the agreement is good in the vicinity of maximum radiation for both RHCP and LHCP as indicated in Figs. 4 and 5. The measured peak gain was found to be approximately $2.0 \mathrm{dBic}$ and the simulated efficiency was $93 \%$ at the center frequency.

To illustrate the circular polarization mechanism, which requires modes of equal magnitude that are phase orthogonal, the simulated surface current distributions viewed from the microstrip side are illustrated in Fig. 6. The direction of the surface currents on the dipole arms and the microstrip feed network is shown at $3.3 \mathrm{GHz}$ as the phase changes from $0^{\circ}$ through $270^{\circ}$. The $0^{\circ}$ phase reference shows that the dominant radiating currents are $+x$ directed, while on the $y$-axis, the microstrip feedline current is phase opposed to each of the groundplane slit 


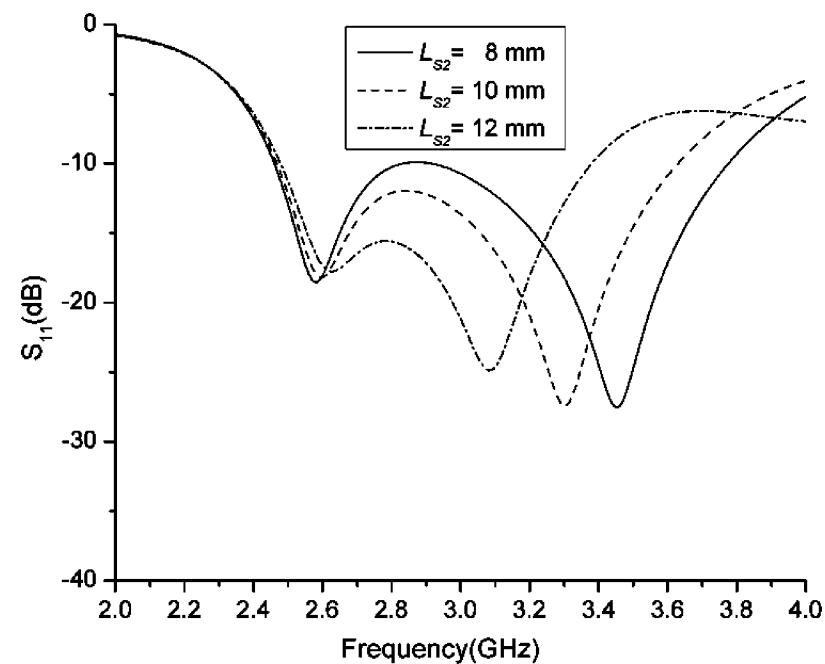

(a)

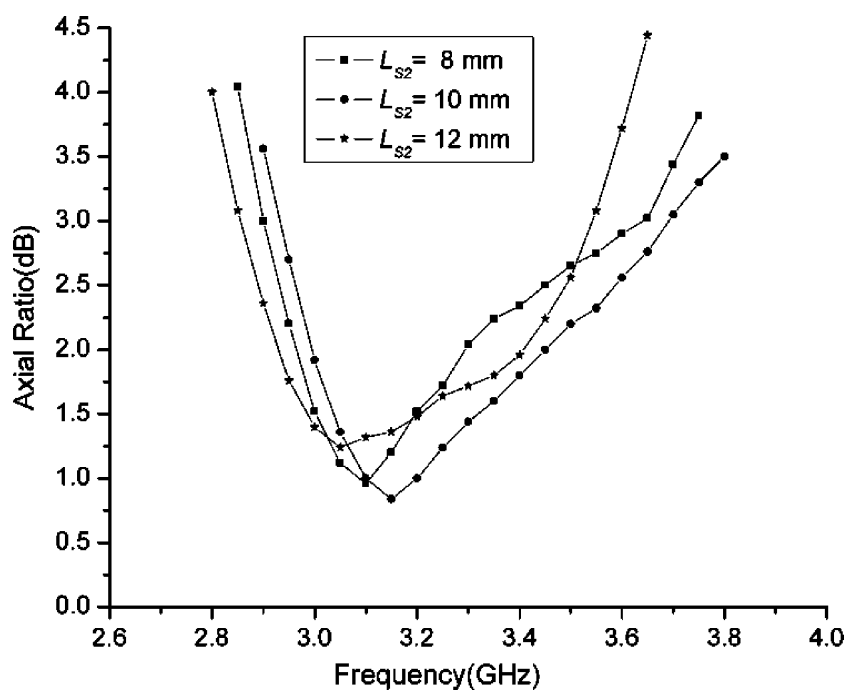

(b)

Fig. 8. (a) Comparison of the $\mathrm{S}_{11}$ for different arm length $L_{\mathrm{S} 2}$ with $W_{1}=$ $1.0 \mathrm{~mm}, L_{g}=12.0 \mathrm{~mm}, W_{g}=2.0 \mathrm{~mm}, S_{L 1}=4.0 \mathrm{~mm}$. (b) Comparison of the AR for different arm length $L_{S 2}$ with $W_{1}=1.0 \mathrm{~mm}, L_{g}=12.0 \mathrm{~mm}$, $W_{g}=2.0 \mathrm{~mm}, S_{L 1}=4.0 \mathrm{~mm}$.

edge currents. For the $90^{\circ}$ phase, the dominant surface current flow is in the $+y$ direction. Currents on the left and right edges of the groundplane slit are in phase opposite directions but the left edge direction is phase aligned with the microstrip feedline. The dipole currents are phase opposed to their respective adjacent groundplane edges. For the $180^{\circ}$ phase, a dominant $-x$ directed current flow is observed, which is an inverted current phase arrangement to the $0^{\circ}$ phase reference. Finally, for the $270^{\circ}$ phase, the currents are $-y$ directed (phase inverted with respect to the $90^{\circ}$ phase), hence the polarization sense is right-hand in the $+z\left(\theta=0^{\circ}\right)$ direction. Furthermore, LHCP may be achieved by interchanging the dipole arms and the microstrip L-shaped feedline via connection, or by simply flipping the antenna $180^{\circ}$ about the vertical centerline parallel to the $y$-axis.

\section{Parametric Study of the Proposed Printed Antenna}

The performance of the proposed printed antenna structure shows greater sensitivity to variation in some parameters, such

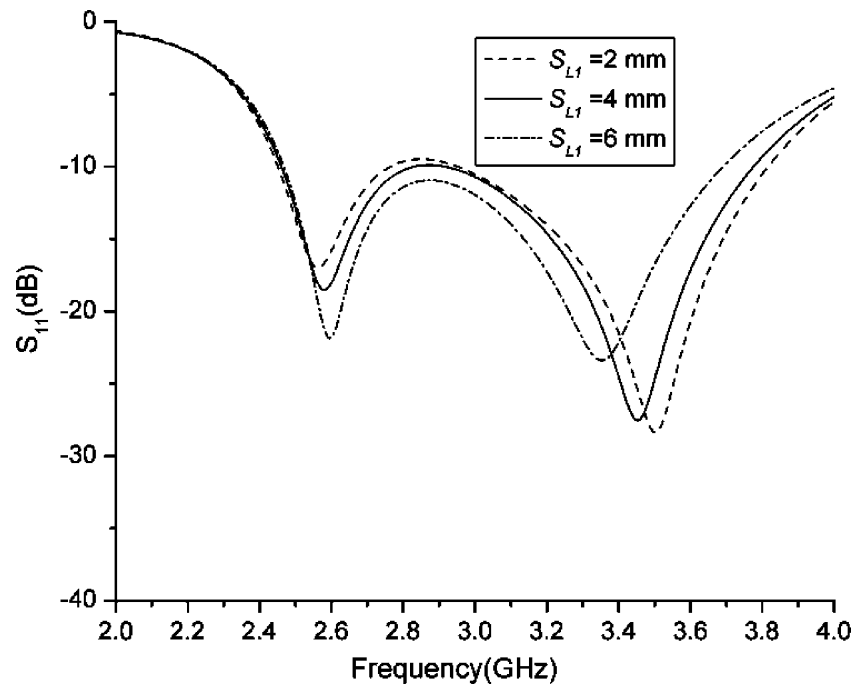

(a)

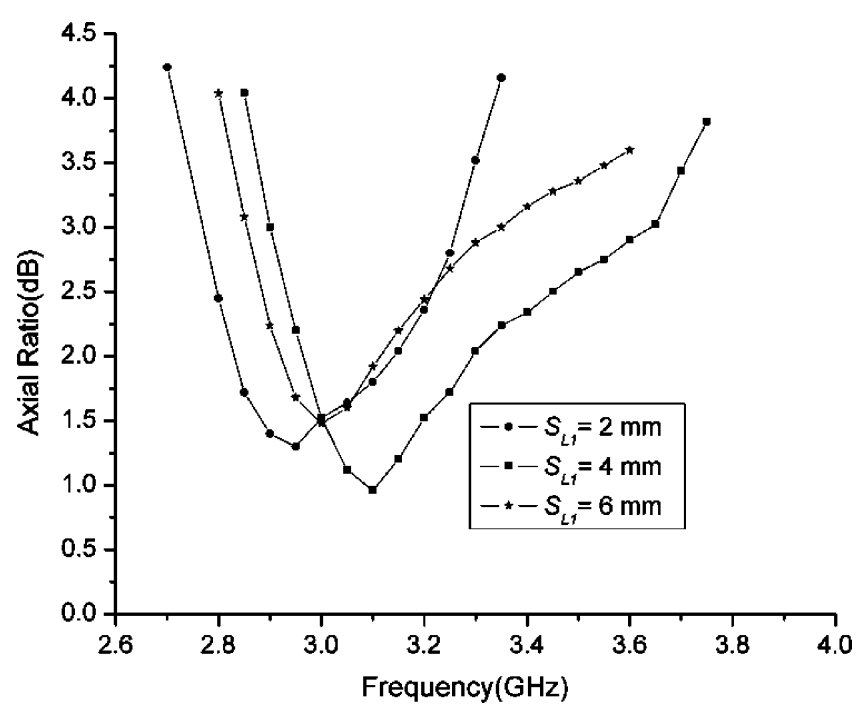

(b)

Fig. 9. (a) Comparison of the $S_{11}$ for different values of $S_{L 1}$ with $W_{1}=$ $1.0 \mathrm{~mm}, L_{S 2}=8.0 \mathrm{~mm}, L_{g}=12.0 \mathrm{~mm}, W_{g}=2.0 \mathrm{~mm}$. (b) Comparison of the AR for different values of $S_{L 1}$ with $W_{1}=1.0 \mathrm{~mm}, L_{S 2}=8.0 \mathrm{~mm}$, $L_{g}=12.0 \mathrm{~mm}, W_{g}=2.0 \mathrm{~mm}$.

as the width $W_{1}$ and length $L_{S 2}$ of the printed dipole arm, the width $W_{g}$ and length $L_{g}$ of the slit between the two feedlines and the location of the microstrip via. A parametric study of these key parameters presented below provides a useful evaluation of their effects on antenna performance. The other parameters for the proposed antenna are listed as follows: $G P=16.0 \mathrm{~mm}$, $S_{L 2}=4.5 \mathrm{~mm}, H_{S}=6.0 \mathrm{~mm}, L_{S 1}=17.0 \mathrm{~mm}, W_{L 1}=$ $3.0 \mathrm{~mm}, W_{L 2}=3.0 \mathrm{~mm}, W_{2}=2.0 \mathrm{~mm}$ (Fig. 1).

\section{A. The Length and Width of the Printed Dipole Arms}

Fig. 7(a) and (b) illustrate plots of $\mathrm{S}_{11}$ and AR against frequency. The variation of the width $W_{1}$ of the two printed arms has little effect on the impedance bandwidth and the frequency of operation. However, as the arm width $W_{1}$ is reduced, the AR is seen to increase as shown in Fig. 7(b). Fig. 8(a) and (b) show the $\mathrm{S}_{11}$ and AR against frequency for different values of the 


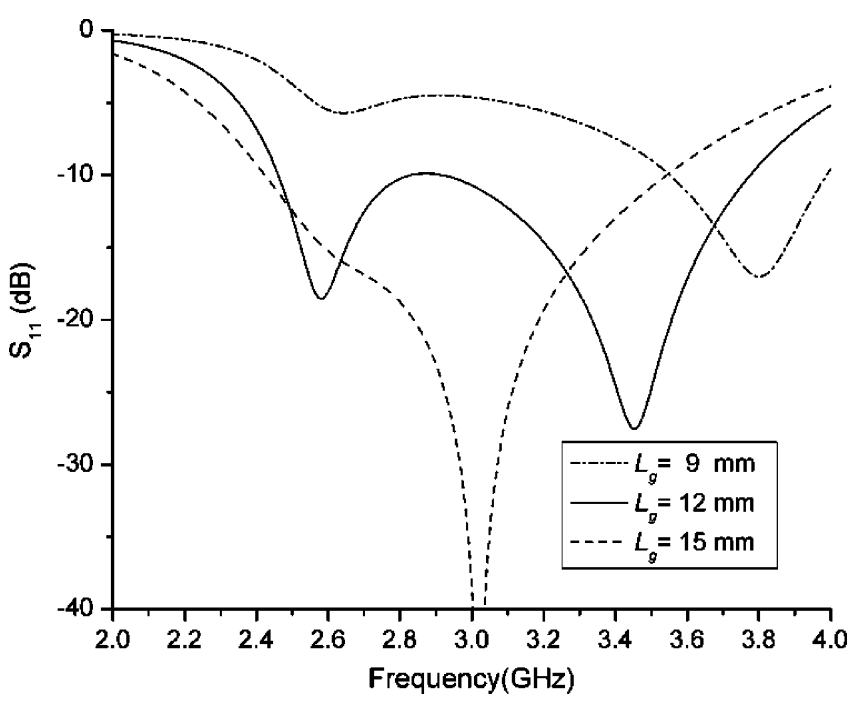

(a)

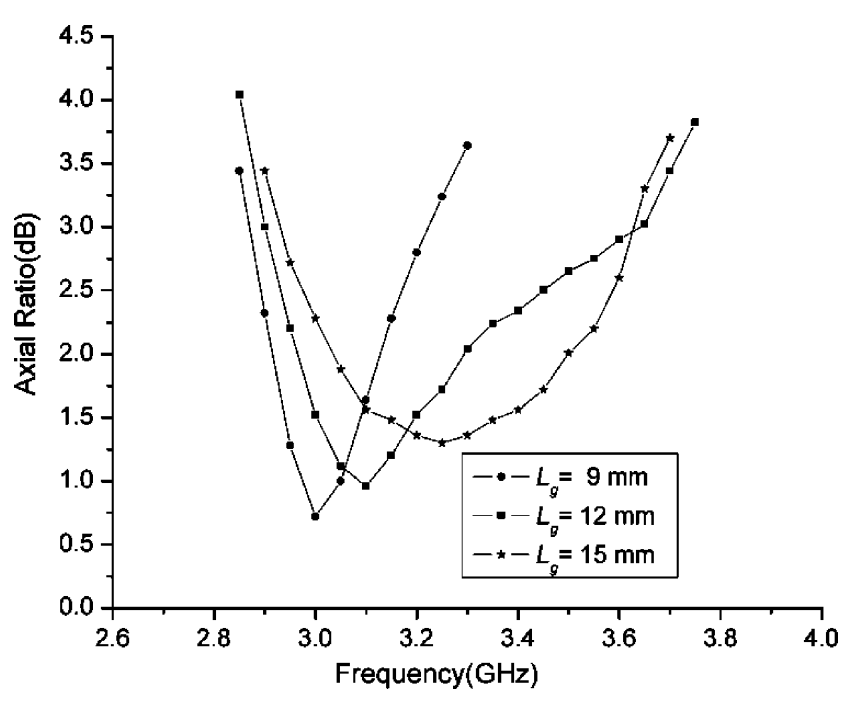

(b)

Fig. 10. (a) Comparison of the $S_{11}$ for various values of slit length $L_{g}$, with $W_{1}=1.0 \mathrm{~mm}, L_{S 2}=8.0 \mathrm{~mm}, W_{g}=2.0 \mathrm{~mm}, S_{L 1}=4.0 \mathrm{~mm}$. (b) Comparison of the AR for various values of slit length $L_{g}$, with $W_{1}=1.0 \mathrm{~mm}$, $L_{S 2}=8.0 \mathrm{~mm}, W_{g}=2.0 \mathrm{~mm}, S_{L 1}=4.0 \mathrm{~mm}$.

short dipole arm length $L_{S 2}$. In this case, the longer arm of the printed dipole is fixed at $L_{S 1}=17.0 \mathrm{~mm}$. As the length of the arm $L_{S 2}$ is shortened from $12 \mathrm{~mm}$ to $8 \mathrm{~mm}$, the $-10 \mathrm{~dB} \mathrm{~S} 11$ bandwidth is significantly increased. It is noted from Fig. 8(b) that the CP bandwidth is shifted downwards as the arm length $L_{S 2}$ is increased.

\section{B. The Location of the Feedpoint Via}

Fig. 9(a) and (b) illustrate the plots of $S_{11}$ and AR for different feedline via locations. The via connection point to the dipole feedline is varied by changing the parameter $S_{L 1}$ while keeping $W_{L 1}$ constant. The AR values are found to be sensitive to the variation of the value of $S_{L 1}$. It is found that the widest AR and impedance bandwidth is obtained for $S_{L 1}=4.0 \mathrm{~mm}$.

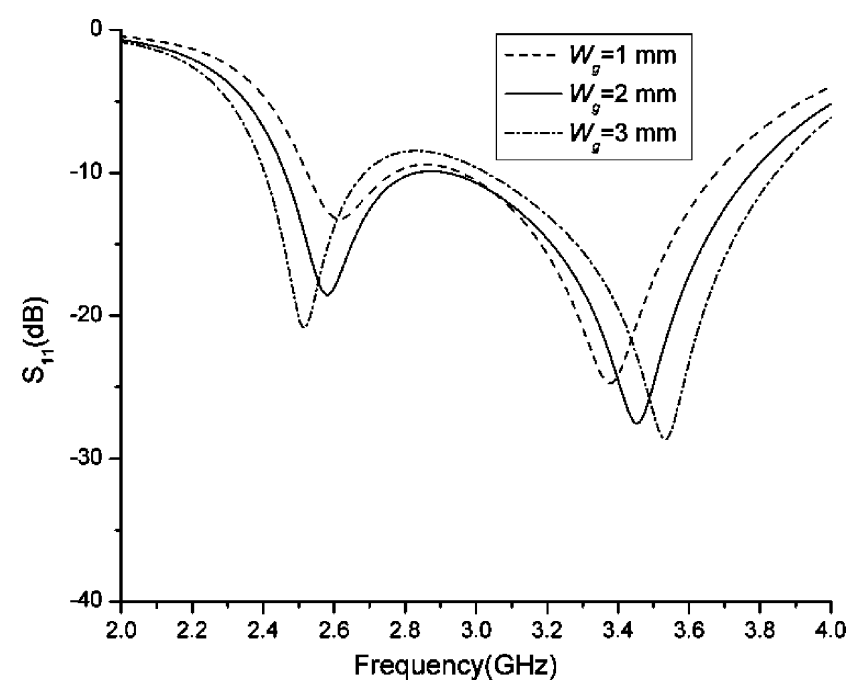

(a)

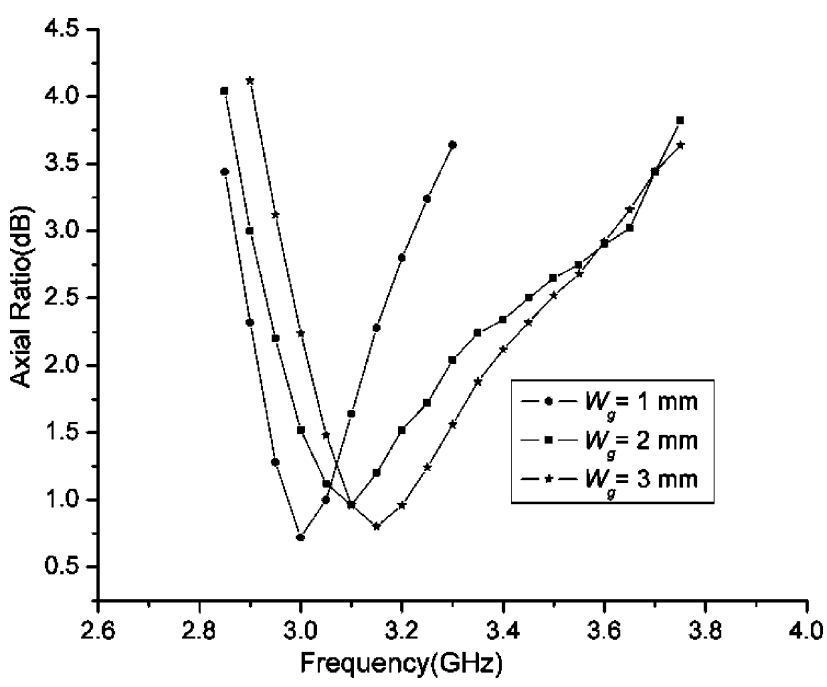

(b)

Fig. 11. (a) Comparison of the $S_{11}$ for various value of slit width $W_{g}$, with $W_{1}=1.0 \mathrm{~mm}, L_{S 2}=8.0 \mathrm{~mm}, L_{g}=12.0 \mathrm{~mm}, S_{L 1}=4.0 \mathrm{~mm}$. (b) Comparison of the AR for various value of slit width $W_{g}$, with $W_{1}=1.0 \mathrm{~mm}$, $L_{S 2}=8.0 \mathrm{~mm}, L_{g}=12.0 \mathrm{~mm}, S_{L 1}=4.0 \mathrm{~mm}$.

\section{The Length and Width of the Slit Between Dipole Feedlines}

The length $L_{g}$ and width $W_{g}$ of the slit between the dipole feedlines was found to have a significant effect on the performance. Fig. 10(a) illustrates the sensitivity of the impedance to variation in the slit length $L_{g}$ (all other parameters are fixed). It is seen that for greatest impedance bandwidth, a value of $L_{g}=12.0 \mathrm{~mm}$ is optimum. A wide AR bandwidth is realized for this value of $L_{g}$ as shown in Fig. 10(b).

Fig. 11 illustrates the sensitivity to the width of the slot $W_{g}$. This parameter was varied from $1 \mathrm{~mm}$ to $3 \mathrm{~mm}$ (while $L_{S 1}, L_{S 2}$ and $W_{2}$ remain constant) and it was found that the widest AR and impedance bandwidth occurred for $W_{g}=2 \mathrm{~mm}$.

This parametric study has helped to identify dimensional trends of the most important parameters and facilitated the design of a wideband circularly polarized antenna. 


\section{CONCLUSIONS}

A novel approach to generate circular polarization using a microstrip-via feedline is presented. The proposed printed antenna element comprises a dipole and ground plane slit which are fed by an L-shaped microstrip-via feed. By the appropriate adjustment of the key dimensional parameters, circular polarization with an axial ratio of $3 \mathrm{~dB}$ or less is realized over a wide bandwidth. The circular polarization mechanism was described using surface currents. Measurements show the $3 \mathrm{~dB}$ axial ratio bandwidth to be approximately $770 \mathrm{MHz}$, representing a fractional bandwidth of approximately $23 \%$ with respect to a centre frequency of $3.3 \mathrm{GHz}$. An impedance bandwidth of $1.34 \mathrm{GHz}$ corresponding to a fractional bandwidth of approximately $42 \%$ with respect to $3.3 \mathrm{GHz}$, is achieved.

\section{REFERENCES}

[1] F. Ferrero, C. Luxey, G. Jacquemod, and R. Staraj, "Dual-band circularly polarized microstrip antenna for satellite applications," IEEE Antennas Wireless Propag. Lett., vol. 4, pp. 13-15, 2005.

[2] X. L. Bao, G. Ruvio, M. J. Ammann, and M. John, "A novel GPS patch antenna on a fractal hi-impedance surface substrate," IEEE Antennas Wireless Propag. Lett., vol. 5, pp. 323-326, 2006.

[3] H. W. Kwa, X. M. Qing, and Z. N. Chen, "Broadband single-fed single-patch circularly polarized antenna for UHF RFID applications," in Proc. IEEE Antennas Propag. Int. Symp., Jul. 2008, pp. 1-4.

[4] A. K. Bhattacharyya and L. Shafai, "A wider band microstrip antenna for circular polarization," IEEE Trans. Antennas Propag., vol. 36, pp. 157-163, 1988.

[5] X. L. Bao and M. J. Ammann, "Comparison of several novel annularring microstrip patch antennas for circular polarization," J. Electromagn. Wave Applicat., vol. 20, no. 11, pp. 1427-1438, 2006.

[6] M. Sumi, K. Hirasawa, and S. Shi, "Two rectangular loops fed in series for broadband circular polarization and impedance matching," IEEE Trans. Antennas Propag., vol. 52, pp. 551-554, 2004.

[7] R. L. Li, J. Laskar, and M. M. Tentzeris, "Wideband probe-fed circularly polarised circular loop antenna," Electron. Lett., vol. 41, no. 18, pp. 997-999, 2005.

[8] S. Gao, Y. Qin, and A. Sambell, "Low-cost broadband circularly polarized printed antennas and array," IEEE Antennas Propag. Mag., vol. 49, no. 4, pp. 57-64, 2007.

[9] R. L. Li, G. DeJean, J. Laskar, and M. M. Tentzeris, "Investigation of circularly polarized loop antennas with a parasitic element for bandwidth enhancement," IEEE Trans. Antennas Propag., vol. 53, pp. 3930-3939, 2005.

[10] S. Shi, K. Hirasawa, and Z. N. Chen, "Circularly polarized rectangularly bent slot antennas backed by a rectangular cavity," IEEE Trans. Antennas Propag., vol. 49, pp. 1517-1524, 2001.

[11] J. S. Row, "The design of a squarer-ring slot antenna for circular polarization,” IEEE Trans. Antennas Propag., vol. 53, pp. 1967-1972, 2005.

[12] C. C. Chou, K. H. Lin, and H. L. Su, "Broadband circularly polarised cross-patch-loaded square slot antenna," Electron. Lett., vol. 43, no. 9, pp. 485-486, 2007.

[13] J. Y. Sze and C. C. Chang, "Circularly polarized square slot antenna with a pair of inverted-L grounded strips," IEEE Antennas Wireless Propag. Lett., vol. 7, pp. 149-151, 2008.

[14] Y. F. Lin, H. M. Chen, and S. C. Lin, "A new coupling mechanism for circularly polarized annular-ring patch antenna," IEEE Trans. Antennas Propag., vol. 56, pp. 11-16, 2008.

[15] K. F. Tong and J. J. Huang, "New proximity coupled feeding method for reconfigurable circularly polarized microstrip ring antennas," IEEE Trans. Antennas Propag., vol. 56, pp. 1860-1866, 2008.

[16] L. C. Kuo et al., "A study of planar printed dipole antennas for wireless communication application," J. Electromagn. Waves Applicat., vol. 21, no. 5, pp. 637-652, 2007.

[17] H. R. Chuang and L. C. Kuo, "3-D FDTD design analysis of a 2.4-GHz polarization-diversity printed dipole antenna with integrated balun and polarization-switching circuit for WLAN and wireless communication applications," IEEE Trans. Microw. Theory Tech., vol. 51, no. 2, pp. 374-381, 2003.

[18] Z. G. Fan, S. Qiao, J. T. Huangfu, and L. X. Ran, "A miniaturized printed dipole antenna with V-shaped ground for $2.45 \mathrm{GHz}$ RFID," Progr. Electromagn. Res., vol. PIER 71, pp. 149-158, 2007.
[19] B. Edward and D. Rees, "A broadband printed dipole with integrated balun,” Microwave Journal, pp. 339-344, May 1987.

[20] F. Tefiku and C. A. Grimes, "Design of broad-band and dual-band antennas comprised of series-fed printed-strip dipole pairs," IEEE Trans. Antennas Propag., vol. 48, no. 6, pp. 895-900, 2000.

[21] K. M. Mak and K. M. Luk, "A shorted cross bowtie patch antenna with a cross dipole for circular polarization," in Proc. IEEE Antennas Propag. Int. Symp., Jun. 2007, pp. 2702-2705.

[22] B. Y. Toh, R. Cahill, and V. F. Fusco, "Understanding and measuring circular polarization," IEEE Trans. Education, vol. 46, pp. 313-318, 2003.

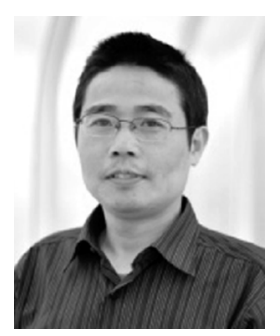

Xiulong Bao (M'09) received the B.Sc. degree in physics from the Huaibei Coal Industry Teachers' College, Anhui Province, China, in July 1991, and the M.Sc. degree in physics and the Ph.D. degree in electromagnetic field and microwave technology from Southeast University, Jiangsu Province, China, in April 1996 and April 2003, respectively.

After graduating, he was a Postdoctoral Researcher at Shanghai Jiaotong University, Shanghai, China, before going to Ireland in 2005. He is currently a Senior Research Associate with the School of Electronic and Communications Engineering, Dublin Institute of Technology, Ireland. His broad research interests include analysis and design of various small and circularly polarized antennas, such as GPS antennas, multiple-band antennas, RFID antennas, a DTV antenna, handset antennas, ultrawideband (UWB) antennas and the design and application of metamaterial/EBG structures. He is also active in the study of electromagnetic scattering, electromagnetic numerical computation (FDTD, PSTD, FDFD and MOM methods) and the study of electromagnetic wave propagation and antenna theory. He has published over 30 peer-reviewed journal papers and 28 conferences articles.

Dr. Bao received funding from Science Foundation Ireland to research miniaturization techniques for broadband, circularly-polarized antennas. He was a Technical Program Committee member for the 65th IEEE Vehicular Technology Conference, Dublin, 2007.

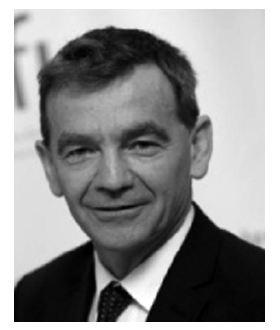

Max Ammann (M'96-SM'08) received the Council of Engineering Institution Part II degree in 1980 and the Ph.D. degree in microwave antenna design from Trinity College, University of Dublin, Dublin, Ireland, in 1997.

$\mathrm{He}$ is a Senior Lecturer in the School of Electronic and Communications Engineering, Dublin Institute of Technology, where he is the Director of the Antenna and High Frequency Research Centre. He also leads the antenna research within Ireland's Centre for Telecommunications Value-chain Research (CTVR), Dublin. He spent eight years on radio systems engineering and antenna design for TCL/Philips Radio Communications Systems, Dublin, where he was responsible for commissioning the Nationwide Communications Network for Ireland's national police force. In 1986 he joined the DIT as a Lecturer and was promoted to Senior Lecturer in 2003. His research interests include electromagnetic theory, antenna miniaturization for terminal and ultra wideband applications, microstrip antennas, metamaterials, antennas for medical devices and the integration with photovoltaic systems. He has in excess of 160 peer-reviewed papers published in journals and international conferences. He has served as an expert to industry on various antenna technologies in the communications, medical, aviation and electronic security sectors in Ireland and abroad. The roles have included design assessment, design solutions, technological strategy reporting and assessment of compliance with international standards on human exposure to electromagnetic energy. The industrial contacts also stem from several successful transfers of fundamental design research into applied solutions.

Dr. Ammann received the 2006 Best Poster Award at the Loughborough Antennas and Propagation Conference, commercialization awards for work with DecaWave Ltd. and Taoglas Ltd and a 2008 CST Publication Award for work on a "Wideband Reconfigurable Rolled Planar Monopole Antenna." He sits on the management committee of the EU COST Action IC0603, "Antenna Systems and Sensors for Information Society Technologies" (ASSIST) and he is active in the Antenna Sensors and Systems Work Centre. As a member of the IEEE International Committee for Electromagnetic Safety, he participated in the revision of the IEEE Std. C95.1, 2005 standard for Safety Levels with Respect to Human Exposure to Radio Frequency Electromagnetic Fields, $3 \mathrm{kHz}$ to $300 \mathrm{GHz}$. He is 
also a member of the URSI Committee for Communications and Radio Science within the Royal Irish Academy, with expertise in Commission K: Electromagnetics in Biology and Medicine. He chaired the IEEE APS Special Session on Antennas for UWB Wireless Communication Systems, Columbus, Ohio, 2003 and was chair for the Antennas and Propagation Track for the 65th IEEE VTC, Dublin 2007. He was the local chair for the October 2008 EU COST IC0603 workshop and meeting in Dublin.

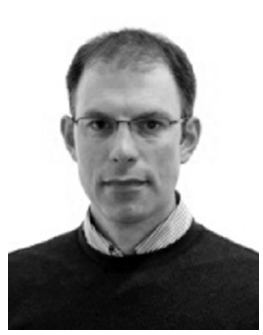

Patrick McEvoy (M'02) received the M.Eng. degree in electronic communications engineering from the University of Hull, Hull, U.K. (partially undertaken at L'Institut Supérieur d'Electronique de Paris, France) in 1998 and the Ph.D. degree in microwave antenna engineering from Loughborough University, Leicestershire, U.K., in 2007.

Currently, he is a senior researcher at the Antenna and High Frequency Research Centre, Dublin Institute of Technology (DIT), Dublin, Ireland. Prior to joining the DIT he was a Research Manager at the
Centre for Mobile Communications Research, Loughborough University, where he worked on switched antennas for handheld terminals, applications of metamaterials, low specific absorption rate antenna design and antenna measurement systems. He has twelve years of applied academic research and industrial experience that includes design, high-volume manufacturing and measurement systems for miniaturized microwave antennas. His research focus is currently on body area communications, hyperthermia applicators, ultra wideband antennas for frequency and time-domain applications and the integration of antennas with solar voltaic devices. He has published over 40 scientific papers and has helped to organize four international conferences on antennas and propagation. 